\title{
Self-Medication Practices among Community of Harar City and Its Surroundings, Eastern Ethiopia
}

\author{
Sara Mamo, ${ }^{1}$ Yohanes Ayele ${ }^{(D)}{ }^{2}$ and Mesay Dechasa ${ }^{2}$ \\ ${ }^{1}$ Wollo Tertiary Care and Teaching Hospital, Wollo, Ethiopia \\ ${ }^{2}$ Department of Clinical Pharmacy, School of Pharmacy, College of Health and Medical Sciences, Haramaya University, Harar, Ethiopia \\ Correspondence should be addressed to Yohanes Ayele; yohanesayele@ymail.com
}

Received 18 April 2018; Revised 1 June 2018; Accepted 6 June 2018; Published 25 July 2018

Academic Editor: Sumio Chono

Copyright (c) 2018 Sara Mamo et al. This is an open access article distributed under the Creative Commons Attribution License, which permits unrestricted use, distribution, and reproduction in any medium, provided the original work is properly cited.

\begin{abstract}
Purpose. Self-medication practice is often associated with irrational medication use. The aim of this study was to assess selfmedication practices among community of Harar City and its surroundings, Eastern Ethiopia. Methods. A cross-sectional study was conducted through exit interview in selected drug outlets of Harar City among 370 clients from March to April, 2017. The data was coded and entered into epi-data and processed and analyzed using SPSS version 20. Results. Many participants practiced selfmedication to alleviate their headache $(30.30 \%)$, to treat their respiratory disorders $(29.50 \%)$, and to treat their gastrointestinal disorders (27\%). More than half $(57.8 \%)$ of study participants declared that they were practicing self-medication due to prior experience and seeking less expensive service (20.50\%). Two-fifths of them (40.3\%) reported pharmacy professionals as source of information while $18.9 \%$ of respondents were advised by neighbors, friends, or relatives. About one-third (31.9\%) of them did not have any source of information for self-medication practice. The most common type of drug used for self-medication by the participants was analgesic (42.2\%). Approximately one-third (31.1\%) of the subjects were expecting to be counseled by the pharmacy professionals about the drug side effects and to be helped in selecting their self-medication drug (30.3\%). Conclusion. Varieties of medications were used among study participants ranging from antipain to that of antibiotics for different complaints including headache, respiratory complaints, and gastrointestinal problems. Experience with drugs and diseases as well as affordability were frequently reported reasons for self-medication practice. Participants had different views toward the role of pharmacy professionals. Hence, it is very important to educate patients on responsible use of medications and create awareness on the role of pharmacist in self-selected medication use in community.
\end{abstract}

\section{Introduction}

According to World Health Organization (WHO), selfmedication is an element of self-care based on selection and use of medicines by individuals to treat self-recognized illnesses or symptoms [1]. Self-medication is practiced for quick and effective relief of symptoms of minor ailments without medical consultations to reduce burden on health care services, most especially in understaffed, inaccessible remote areas $[2,3]$.

Self-medication has a positive impact on individuals and health care systems if practiced correctly. It allows patients to take responsibility, build confidence to manage their own health, and save time spent in waiting for a doctor, and it may help to decrease health care costs $[1,4,5]$. Nevertheless, self-medication practice is highly prone to inappropriate use and has its own drawbacks resulting in wastage of resources, increased resistance of pathogens, and increased adverse reaction $[6,7]$. Self-medication practices can also lead to incorrect self-diagnosis, delays in seeking appropriate care, dangerous drug interactions, incorrect dosage, incorrect choice of medication, and risk of dependence and drug abuse $[2,8]$.

Study conducted in different setting indicates high prevalence of self-medication practice [9-11]. In order to reduce irrational medication use due to self-medication, community pharmacy professionals can play key role through providing support and advice about medicines to the general public [1215]. However, studies showed poor understanding of public on the role of community pharmacist in self-care $[16,17]$. 
In developing countries like Ethiopia, people are using not only nonprescription drugs but also prescription drugs without supervision [18]. However, there is no study done in Harar City, Eastern Ethiopia, on the current status of self-medication practices and communities' view toward the role of community pharmacy professionals. Hence, this study aimed to assess self-medication practices and public perspectives toward role of community pharmacy professionals in Harar City.

\section{Materials and Methods}

2.1. Study Area and Period. This study was conducted among community of Harar City and its surroundings from March to April, 2017. Harar, the capital city of Harari regional state, is located in the Eastern part of Ethiopia, at a distance of 525 Km from Addis Ababa, the capital city of Ethiopia. During the study period there were 16 pharmacies and 44 drug stores in the Harar City.

2.2. Study Design and Study Population. A cross-sectional study was conducted among clients who visited drug outlets during study period. All residents of Harar City and its surroundings were the source populations and all clients who visited selected private drug retail outlets for selfmedication within the study period were the study populations. Participants aged $18+$ who purchased medication without prescription were included in the study. Clients who presented to collect drugs for other clients were excluded from the study.

2.3. Sample Size and Sampling Technique. The actual sample size for the study was determined using the formula for single population proportion by assuming 5\% marginal error, $95 \%$ confidence interval, $\partial$ (alpha) $=0.05$, and $50 \%$ of the prevalence rate of self-medication to get total sample size of 384. Stratified random sampling technique was used to select representative drug retail outlet. For each selected drug retail outlets, number of the participants to be interviewed was allocated based on patient flow to the selected outlets.

2.4. Data Collection and Analysis. A structured questionnaire was used for data collection. The pretest was conducted to check the functionality of the tools. The training was given for data collectors on the content of data collection tools and ways of approaching the interviewee. After the data collection, the questionnaires were checked for its completeness and consistency. Finally, it was coded and entered into epidata, processed, and analyzed using SPSS version 20. The findings were presented by frequencies, percentages, and summary measures and displayed using tables.

2.5. Ethical Consideration. The study protocol was approved by the school of pharmacy research ethics review committee, Haramaya University. A formal permission letter was obtained from College of Health and Medical Sciences and submitted to drug retail outlets managers and the purpose of the research and how its premise is selected were also communicated. Before the data collection, verbal consent was obtained from each participant by informing them of the purpose of the study.

\subsection{Operational Definitions}

Pharmacy Professionals. Pharmacy practitioners who were working in drug outlets regardless of their educational level.

Drug Outlets. Refers to both community pharmacies and drug stores.

\section{Results}

3.1. Sociodemographic Characteristics of Participants. A total of 370 clients visiting drug outlets in Harar City participated in the survey while further 14 refused to participate, giving a response rate of $96.4 \%$. The mean age of respondents was of 32 with a standard deviation of 11.15 years. Proportion of females was $53 \%$ as compared to males. More than half $(54.9 \%)$ of respondents were married. Regarding economic status, the mean and standard deviation of respondents monthly income was 3179 and 2643.66, ETB, respectively. Table 1 shows sociodemographic characteristics of participants.

3.2. Self-Medication Practice of Participants. As it is indicated in Table 2, about one-third (30.3\%) of the subjects used self-medication to alleviate their headache, to treat their respiratory disorders $(29.5 \%)$, and to treat their gastrointestinal disorders (27\%). When asked about the reason for self-medication, more than half $(57.8 \%)$ respondents mentioned their previous experience while $20.50 \%$ of them practiced self-medication seeking less expensive drug or service. Regarding their source of the information, on selfmedication, two-fifths of them (40.3\%) reported pharmacy professionals as source of information while $18.9 \%$ of respondents were advised by neighbors, friends, or relatives. About one-third $(31.9 \%)$ of them did not have any source of information for self-medication practice. In this study, analgesic was the most commonly (42.2\%) used medicine followed by respiratory drugs (31.1\%) and gastrointestinal drugs (19.50\%).

3.3. Participants' Ways of Request for Self-Medication. As to patients approach to requesting a self-medication, about half of the subjects collected the medication by telling professionals the name of the drug while $43 \%$ of them asked professionals by telling them their symptoms. Participants were also quizzed about their expectation from pharmacy professionals. Just under one-third of respondents (31.1\%) expected to be counseled by the pharmacy professionals about the drug side effects and how to avoid them and $30.3 \%$ of them were expecting help in the drug selection process (Table 3).

\section{Discussion}

The primary objective of this study was to assess selfmedication practices among community of Harar City. In this study, the common chief compliant was headache and respiratory and gastrointestinal disorders. The major deriving 
TABLE 1: Sociodemographic characteristics of participants in Harar City and its surroundings from March to April, 2017 $(n=370)$.

\begin{tabular}{|c|c|c|}
\hline Variable & Frequency & Percentage (\%) \\
\hline \multicolumn{3}{|l|}{ Age (years) } \\
\hline $18-25$ & 123 & 33.2 \\
\hline $26-33$ & 128 & 34.6 \\
\hline 34 and above & 119 & 32.2 \\
\hline Mean (SD) & $32(11.15)$ & \\
\hline \multicolumn{3}{|l|}{ Gender } \\
\hline Female & 196 & 53.0 \\
\hline Male & 174 & 47.0 \\
\hline \multicolumn{3}{|l|}{ Ethnicity } \\
\hline Oromo & 126 & 34.1 \\
\hline Amhara & 118 & 31.9 \\
\hline Hader & 56 & 15.1 \\
\hline Tigre & 28 & 7.6 \\
\hline Somali & 16 & 4.3 \\
\hline Others & 26 & 7 \\
\hline \multicolumn{3}{|l|}{ Religion } \\
\hline Orthodox & 175 & 47.3 \\
\hline Muslim & 154 & 41.6 \\
\hline Protestant & 34 & 9.2 \\
\hline Others & 7 & 1.9 \\
\hline \multicolumn{3}{|l|}{ Educational } \\
\hline Illiterate & 27 & 7.3 \\
\hline Read and write & 10 & 2.7 \\
\hline Primary school & 39 & 10.5 \\
\hline Secondary school & 94 & 25.4 \\
\hline College and above & 200 & 54.1 \\
\hline \multicolumn{3}{|l|}{ Marital status } \\
\hline Single & 136 & 36.8 \\
\hline Married & 203 & 54.9 \\
\hline Divorced & 18 & 4.8 \\
\hline Widowed & 13 & 3.5 \\
\hline \multicolumn{3}{|l|}{ Occupations } \\
\hline Merchant & 145 & 39.2 \\
\hline Employee & 107 & 28.9 \\
\hline Daily labor & 37 & 10 \\
\hline House wife & 63 & 17 \\
\hline Others & 18 & 4.9 \\
\hline \multicolumn{3}{|l|}{ Monthly income } \\
\hline Nondisclosed & 175 & 47.3 \\
\hline $400-2000$ & 78 & 21.1 \\
\hline $2001-3600$ & 63 & 17.0 \\
\hline $3601-5200$ & 12 & 3.2 \\
\hline$>5201$ & 42 & 11.4 \\
\hline Mean (SD) & 3179(2643.66) Birr & \\
\hline
\end{tabular}

* ETB, Ethiopian Birr, \$1=28ETB, SD: standard deviation.

reason for self-medication was previous experience of drugs and disease and cheapness of such practice compared to visiting health care setting such as clinic and hospitals.
Pharmacy professionals followed by neighbors, friends, or relatives were the main source of information for selfmedication practice. In this study, analgesic was the most commonly used medicine followed by respiratory drugs and gastrointestinal drugs.

In this study, headache compliant was leading (30.3\%) cause for self-medication followed by respiratory $(29.5 \%)$ and gastrointestinal disorders (27\%). A systematic review conducted in Ethiopia reported fever/headache, gastrointestinal tract diseases, and respiratory diseases as the commonest illnesses for which self-medication was taken, accounting for an average of $30.5 \%, 19.7 \%$, and $18.3 \%$ of self-medication use, respectively [18]. This finding is also consistent with studies done elsewhere [19-21]. For the aforementioned complaints self-medications seem more logical than visiting doctors because often the pharmacy is most easily accessible and more time-saving. Although those symptoms seem less severe and manageable, pharmacy professionals and patients have to be familiar with alarming signs and symptoms that require physicians' visit. In addition, pharmacy professionals should reassure clients without recommending drugs as not all illness require medication.

In our study, majority of study subjects (57.8\%) declared that they were practicing self-medication since they have had prior experience while $20.5 \%$ of them practiced selfmedication because of its affordability. Mildness of the ailments was also frequently stated as a reason. This result is in agreement with study done elsewhere [22-24]. In spite of cheapness of self-medication practice, there might be long term underlining health damage for certain medical cases if they are not managed timely and properly. Hence pharmacy professional should be familiar with such medical cases and should alert clients regarding appropriate actions.

In the present study, the most common sources of information were pharmacy professionals (40.3\%) and selfdecision without any information (31.9\%), followed by neighbors, friends, or relatives (18.9\%) and from reading drug related materials $(8.1 \%)$ such as labels, leaflets, or promotion about the medication. A Study done in Jimma town showed that about $48.02 \%$ of self-medicated individual's source of information was reported from personal drug outlets [22] which is almost similar to this study. However, study conducted in Mekele reported common information sources for self-medication as self-decision (64.00\%), friends (31.25\%), and media and reading material $(14.10 \%)$, while the least common information source for self-medication was pharmacy professionals or druggists (9.40\%) which is in contrast with this study [25]. This disagreement might be due to the difference in study population as a later study was conducted among university students. It is understandable that the users get information for self-medication from different sources. However, the community should be aware of the fact that not all sources of information are genuine and be able to prove the truthfulness of information.

Regarding category of drugs used for self-medication, in current study, analgesics were most commonly used drugs (42.2\%), followed by drugs taken for respiratory problem (31.10\%) and gastrointestinal drugs (19.50\%). This finding is in line with studies conducted elsewhere $[17,20]$. However, 
TABLE 2: Self-medication practice among participants in Harar City and its surroundings from March to April, 2017(n=370).

\begin{tabular}{|c|c|c|c|}
\hline Variables & Responses & Frequency & Percentage (\%) \\
\hline \multicolumn{4}{|c|}{ Major chief complaints } \\
\hline & Headache & 112 & 30.3 \\
\hline & Respiratory disorders & 109 & 29.5 \\
\hline & Gastrointestinal disorders & 100 & 27.0 \\
\hline & Fever & 26 & 7.0 \\
\hline & Skin disorders & 23 & 6.2 \\
\hline \multicolumn{4}{|c|}{ Reason for self-medication } \\
\hline & Less expensive & 76 & 20.5 \\
\hline & Prior experience of drug or disease & 214 & 57.8 \\
\hline & Disease is not serious & 49 & 13.2 \\
\hline & Emergency care & 30 & 8.1 \\
\hline & Others* & 1 & 0.3 \\
\hline \multicolumn{4}{|c|}{ Sources of information } \\
\hline & Pharmacist & 149 & 40.3 \\
\hline & No information & 118 & 31.9 \\
\hline & Advised by neighbors, friends, or relatives & 70 & 18.9 \\
\hline & Labels and leaflets or promotional materials & 30 & 8.1 \\
\hline & Others^ & 3 & 0.8 \\
\hline \multicolumn{4}{|c|}{ Medications used } \\
\hline & Analgesic / antipyretics & 156 & 42.2 \\
\hline & Respiratory drugs & 115 & 31.1 \\
\hline & GI drugs & 72 & 19.5 \\
\hline & Oral rehydration salt & 2 & 0.5 \\
\hline & Antimicrobials & 11 & 3.0 \\
\hline & Others $* *$ & 14 & 3.8 \\
\hline \multicolumn{4}{|c|}{ Adverse drug reaction } \\
\hline & Yes & 44 & 11.9 \\
\hline & No & 326 & 88.1 \\
\hline
\end{tabular}

* indicates less waiting time; $\wedge$ indicates other professionals, past experiences; $* *$ indicates vitamins and anthelmintics.

TABle 3: Participants' ways of request for self-medication in Harar city and its surroundings from March to April, 2017(n=370).

\begin{tabular}{|c|c|c|c|}
\hline Variables & Responses & Frequency & Percentage (\%) \\
\hline \multicolumn{4}{|c|}{ Self-medication request } \\
\hline & By telling professionals the symptom of illness & 159 & 43 \\
\hline & By telling professionals the name of the drug & 183 & 49.5 \\
\hline & By showing an old sample/package of the drugs & 16 & 4.3 \\
\hline & By describing the physical characteristics of the drugs & 12 & 3.2 \\
\hline \multicolumn{4}{|c|}{ Participants expectation from pharmacy professionals } \\
\hline & To counsel them about drug side effects and how to avoid it & 115 & 31.1 \\
\hline & To help them in selecting drugs & 112 & 30.3 \\
\hline & To counsel them about diseases & 76 & 20.5 \\
\hline & To monitor their health's progress to ensure the safety and effectiveness of drugs & 35 & 9.5 \\
\hline & To label their drugs for self-medication & 32 & 8.6 \\
\hline
\end{tabular}

the major difference was seen on report regarding antimicrobial use. In our study, only $3 \%$ of participants reported antimicrobial use. This might be due to participants' lack of understanding about type of drugs they used. Although fewer participants reported use of antibiotics, it is very important to discourage self-medication with antibiotics.
Public is expected to trust and benefit from expertise of community pharmacy professionals on medication related issues. Nevertheless, in this study, only $31.1 \%$ of participants were expecting consultation from pharmacy professionals about the drug side effects and only $30.3 \%$ of them were seeking help in selection of self-medication drug which is 
relatively low compared to study done elsewhere $[9,26]$. This disparity may be due difference in study area which shows lack of awareness on role of community pharmacy professionals in this study area. Community pharmacy professionals can play significant role in primary care because of their easy access to the community. However, these professionals are often underutilized due to different reasons; one of the reasons being community lack of awareness about potential roles and mistrust. Hence, it is very important to create awareness among community about the roles and capabilities of community pharmacy personnel regarding the medication related issues.

\section{Conclusions}

In present study, headache, respiratory complaints, and gastrointestinal problems were common reasons for which patient sought self-medication. The practitioners also mentioned their previous experience and affordability of the drug in pharmacy as deriving factors. Although many selfmedication users had information about the drug from pharmacist, significant number of subjects had no knowledge about the medication they used. Antipain medications were the most commonly used medicine followed by respiratory drugs and gastrointestinal drugs. In current study, requesting the medicine by telling professionals the name of the drug was common followed by asking professionals by telling them their symptoms. Furthermore, participants had different views toward the role of pharmacy professionals.

\section{Data Availability}

The data used to support the findings of this study are available from the corresponding author upon request.

\section{Additional Points}

Limitations of the Study. We were not able to establish cause and effect relationship since we included only participants who were in drug outlets for self-medication in the study. The present study had also limitations regarding its generalizability as it was not conducted in multicenter.

\section{Conflicts of Interest}

The authors have no conflicts of interest to disclose.

\section{Acknowledgments}

The authors want to extend their special gratitude to the respondents, the data collectors, and the owners (workers) of selected private drug retail outlets who gave them permission and helped them in data collection process.

\section{References}

[1] WHO, "The Role of the pharmacist in self-care and selfmedication. Report of the 4th WHO consultative group on the role of the pharmacist," Tech. Rep., World Health Organization, The Hague, the Netherlands, 1998.
[2] D. Bennadi, "Self-medication: a current challenge," Journal of Basic and Clinical Pharmacy, vol. 5, no. 1, pp. 19-23, 2014.

[3] V. Phalke, D. Phalke, and P. Durgawale, "Self-medication practices in rural Maharashtra," Indian Journal of Community Medicine, vol. 31, no. 1, p. 34, 2006.

[4] O. A. Abosede, "Self-medication: An important aspect of primary health care," Social Science \& Medicine, vol. 19, no. 7, pp. 699-703, 1984.

[5] C. M. Hughes, J. C. McElnay, and G. F. Fleming, "Benefits and risks of self medication," Drug Safety, vol. 24, no. 14, pp. 10271037, 2001.

[6] A. Panda, S. Pradhan, G. Mohapatra, and J. Mohapatra, "Drugrelated problems associated with self-medication and medication guided by prescription : A pharmacy-based survey," Indian Journal of Pharmacology, vol. 48, no. 5, pp. 515-521, 2016.

[7] S. Fainzang, "Managing medicinal risks in self-medication," Drug Safety, vol. 37, no. 5, pp. 333-342, 2014.

[8] M. E. Ruiz, "Risks of self-medication practices," Current Drug Safety, vol. 5, no. 4, pp. 315-323, 2010.

[9] S. A. Akshar, P. Z. Metwaly, and D. M. Shamssain, "Patients' perceptions of community pharmacy practice in UAE: an overview," IOSR Journal of Pharmacy, vol. 04, no. 11, pp. 08-14, 2014.

[10] A. Suleiman, "Self-medication and the advisory role of pharmacists in Riyadh, Saudi Arabia," Archives of Pharmacy Practice, vol. 4, no. 4, p. 180, 2013.

[11] A. D. Kassie, B. B. Bifftu, and H. S. Mekonnen, "Self-medication practice and associated factors among adult household members in Meket district," BMC Pharmacology \& Toxicology, vol. 19, article 15, 2018.

[12] P. Rutter, "Role of community pharmacists in patients self-care and self-medication," Integrated Pharmacy Research \& Practice, vol. 4, pp. 57-65, 2015.

[13] J. P. Shaw and M. A. Trevean, "The advisory role of the community pharmacist in self-medication," The New Zealand Medical Journal, vol. 96, no. 727, pp. 171-173, 1983.

[14] J. Bell, G. Dziekan, C. Pollack, and V. Mahachai, "Self-care in the twenty first century: a vital role for the pharmacist," Advances in Therapy, vol. 33, no. 10, pp. 1691-1703, 2016.

[15] A. Piecuch and M. Kozłowska-Wojciechowska, "Self-medication in Poland: The pharmacist's advisory role in Warsaw," International Journal of Clinical Pharmacy, vol. 35, no. 2, pp. 225-229, 2013.

[16] J. H. You, F. Y. Wong, F. W. Chan, E. L. Wong, and E.-K. Yeoh, "Public perception on the role of community pharmacists in self-medication and self-care in Hong Kong," BMC Clinical Pharmacology, vol. 11, article 19, 2011.

[17] R. Al-Ramahi, "Patterns and attitudes of self-medication practices and possible role of community pharmacists in Palestine," International Journal of Clinical Pharmacology and Therapeutics, vol. 51, no. 7, pp. 562-567, 2013.

[18] M. B. Ayalew, "Self-medication practice in Ethiopia: A systematic review," Patient Preference and Adherence, vol. 11, pp. 401413, 2017.

[19] A. R. Sapkota, M. E. Coker, R. E. Rosenberg Goldstein et al., "Self-medication with antibiotics for the treatment of menstrual symptoms in southwest Nigeria: a cross-sectional study," BMC Public Health, vol. 10, no. 1, article 610, 2010.

[20] A. Ahmad, M. U. Khan, A. B. Srikanth, I. Patel, A. N. Nagappa, and S. Q. Jamshed, "Evaluation of workload and its impact on satisfaction among pharmacy academicians in Southern India," 
Journal of Clinical and Diagnostic Research, vol. 9, no. 6, pp. FC01-FC06, 2015.

[21] M. Shafie, M. Eyasu, K. Muzeyin, Y. Worku, S. Martín-Aragón, and N. Kumar, "Prevalence and determinants of self-medication practice among selected households in Addis Ababa community," PLoS ONE, vol. 13, no. 3, Article ID e0194122, 2018.

[22] S. Worku and A. G/Mariam, "Practice of self-medication in Jimma Town," Ethiopian Journal of Health Development, vol. 17, no. 2, pp. 111-116, 2004.

[23] W. Sweileh, "Self-medication and over-the-counter practices: a study in Palestine," Journal of al-Aqsa University, vol. 8, pp. 1-9, 2004.

[24] T. Eticha and K. Mesfin, "Self-medication practices in Mekelle, Ethiopia," PLoS ONE, vol. 9, no. 5, Article ID e97464, 2014.

[25] G. B. Gutema, D. A. Gadisa, Z. A. Kidanemariam et al., "Self-medication practices among health sciences students: the case of Mekelle University," Journal of Applied Pharmaceutical Science, vol. 1, no. 10, pp. 183-189, 2011.

[26] M. A. Hassali, A. A. Shafie, H. Al-Qazaz, J. Tambyappa, S. Palaian, and V. Hariraj, "Self-medication practices among adult population attending community pharmacies in Malaysia: an exploratory study," International Journal of Clinical Pharmacy, vol. 33, no. 5, pp. 794-799, 2011. 

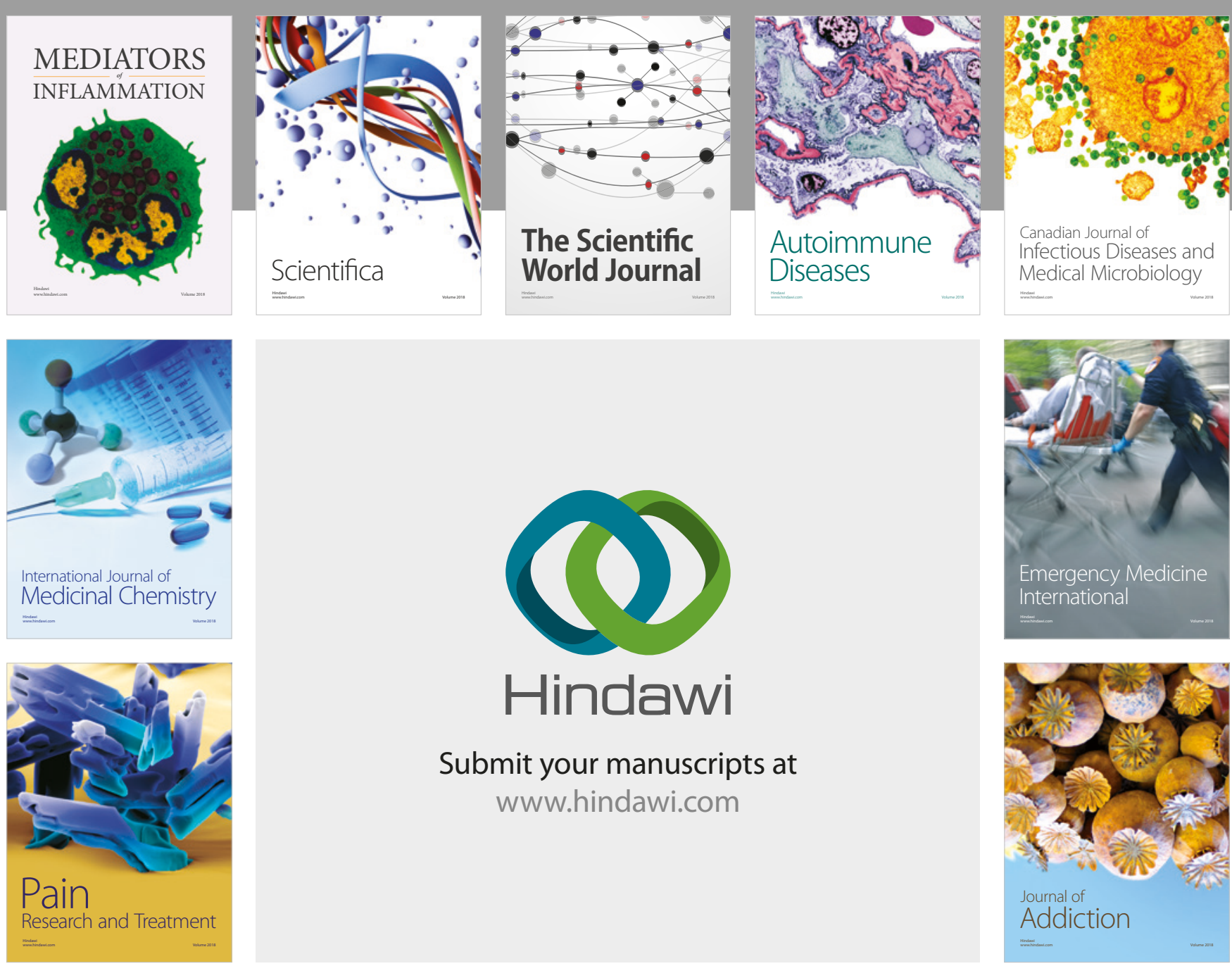

Canadian Journal of
Infectious Diseases and Medical Microbiology

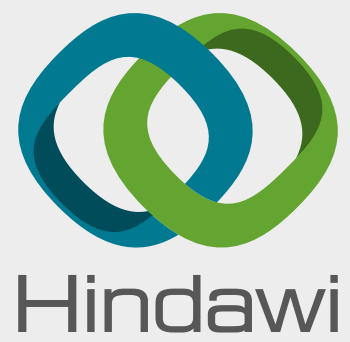

Submit your manuscripts at

www.hindawi.com
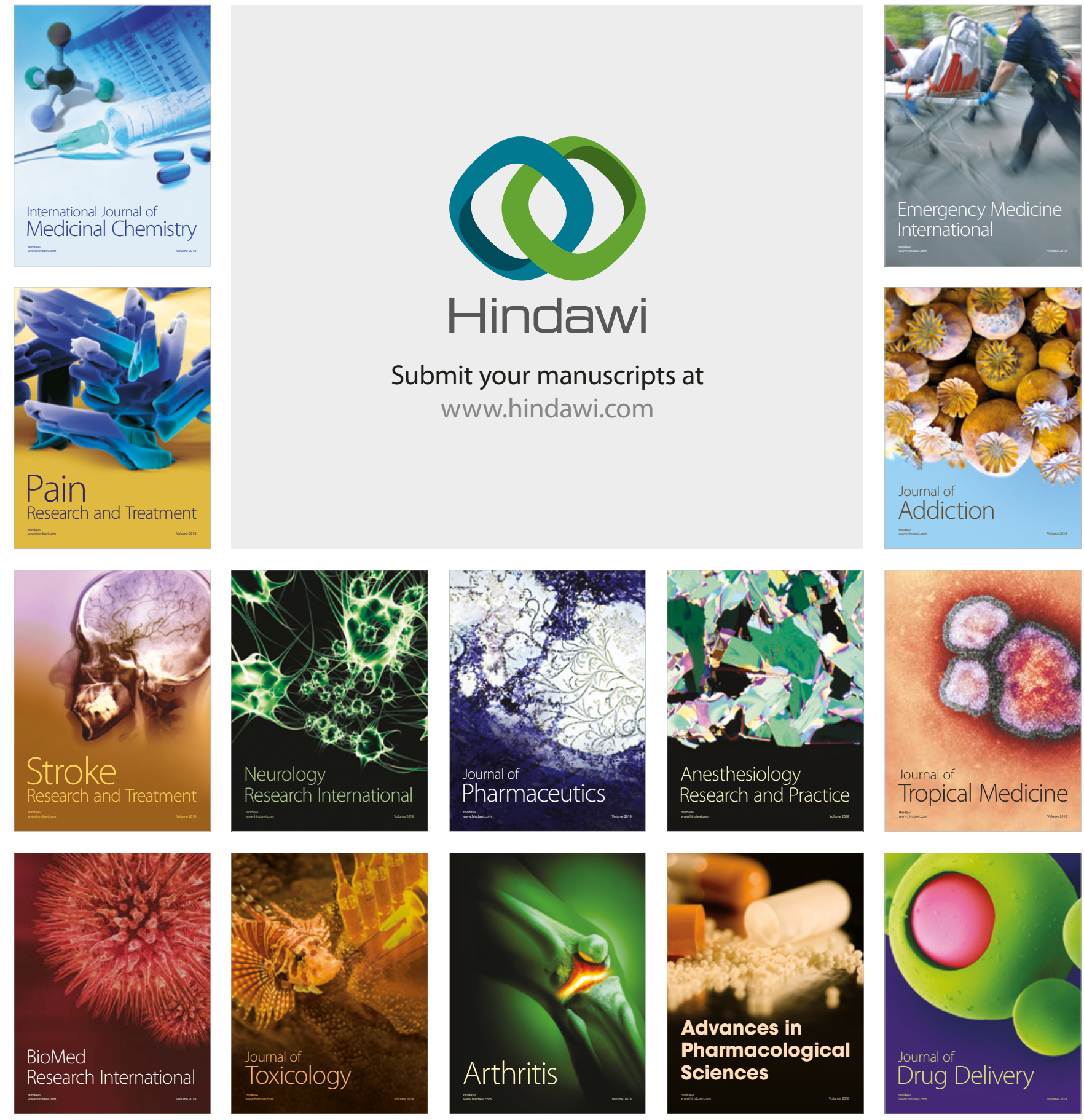